\title{
Non-bronchial causes of haemoptysis: imaging and interventions
}

\author{
Manphool Singhal ${ }^{1 \mathrm{~A}, \mathrm{~B}, \mathrm{D}, \mathrm{E}, \mathrm{F}}$, Anupam Lal ${ }^{1 \mathrm{D}, \mathrm{E}}$, Nidhi Prabhakar ${ }^{1 \mathrm{~B}, \mathrm{C}, \mathrm{E}, \mathrm{F}}$, Mukesh K. Yadav ${ }^{1 \mathrm{~B}, \mathrm{E}}$, Rajesh Vijayvergiya ${ }^{2 B, D, E}$, \\ Digamber Behra ${ }^{3 A, E}$, Niranjan Khandelwal ${ }^{1 A, D, E}$
}

'Department of Radiodiagnosis and Imaging, Postgraduate Institute of Medical Education and Research, Chandigarh-160012, India 2Department of Cardiology, Postgraduate Institute of Medical Education and Research, Chandigarh-160012, India

${ }^{3}$ Department of Pulmonary Medicine, Postgraduate Institute of Medical Education and Research, Chandigarh-160012, India

\section{Abstract}

Purpose: To describe non-bronchial causes of haemoptysis on imaging and the role of interventional radiology in their management from cases of haemoptysis archived from our database at a tertiary care, federally funded institution.

Material and methods: Retrospective analysis of cases that presented with haemoptysis in our institution from 2008 to 2013 was done, and details of cases in which the bleeding was from a non-bronchial source were archived and details of imaging and treatment were recorded.

Results: Retrospective analysis of patients presenting with haemoptysis yielded $24(n=24)$ patients having haemoptysis from non-bronchial sources. Causes of haemoptysis were: Rasmussen aneurysms $(n=12 / 24)$, costocervical trunk pseudoaneurysm $(n=1 / 24)$, left internal mammillary artery pseudoaneurysm $(n=1 / 24)$, left ventricular aneurysms $(n=3 / 24)$, pulmonary arteriovenous malformations (AVMs) $(n=5 / 24)$, and proximal interruption of pulmonary artery $(n=2 / 24)$. Imaging and interventional radiology management are described in detail.

Conclusions: Haemoptysis can be from non-bronchial sources, which may be either from systemic or pulmonary arteries or cardio-pulmonary fistulas. Bronchial computed tomography angiography (CTBA), if feasible, must always be considered before bronchial artery embolisation because it precisely identifies the source of haemorrhage and vascular anatomy that helps the interventional radiologist in pre-procedural planning. This circumvents chances of re-bleed if standard bronchial artery embolisation is done without CTBA.

Key words: haemoptysis, non-bronchial causes, bronchial CT angiography, digital subtraction angiography, embolisation.

\section{Introduction}

Bleeding from the lower respiratory tract is called haemoptysis [1]. It has been variously categorised as massive or life threatening. Massive haemoptysis is defined as bleeding more than $300 \mathrm{ml}$ in a day [2], while life threatening haemoptysis is defined as haemoptysis that causes sufficient respiratory impairment and threatens life [3].

The cause of haemoptysis is increased vascularisation of lung parenchyma by bronchial and non-bronchial systemic arteries. Common conditions causing haemoptysis are due to infections (tuberculosis or fungal infections), chronic bronchitis, bronchiectasis, and malignancy [4]. Bronchial arteries are the most common cause of haemoptysis in more than $90 \%$ of cases [5]. Non-bronchial systemic arteries may also cause haemoptysis and include intercostals arteries, inferior phrenic arteries, internal mammary arteries, and collaterals from intercostal and subclavian arteries [6]. The pulmonary artery may also cause haemoptysis as a sequel of infection, trauma, or vasculitis [7].

In this article we describe imaging and interventional treatment of various conditions in which haemoptysis was from non-bronchial sources.

\section{Correspondence address:}

Dr. Manphool Singhal, Department of Radiodiagnosis and Imaging, Postgraduate Institute of Medical Education and Research, Chandigarh, Madhya Marg,

Sector 12, Chandigarh-160012, India, e-mail: drmsinghal@yahoo.com

\section{Authors' contribution:}

A Study design · B Data collection · C Statistical analysis · D Data interpretation · E Manuscript preparation · F Literature search · G Funds collection 


\section{Material and methods}

Retrospective analysis of cases that presented with haemoptysis and were managed in our institution from 2008 to 2013 was done. Cases in which the bleeding was from non-bronchial sources were recorded and details archived. Our institution is a non-profit, federally funded tertiary care institute located in north India.

\section{Results}

Retrospective analysis of patients presenting with haemoptysis yielded 24 patients having haemoptysis from nonbronchial sources. Causes of haemoptysis were: Rasmussen aneurysms $(n=12)$, costocervical trunk pseudoaneurysm $(n=1)$, left internal mammillary artery pseudoaneurysm $(n=1)$, left ventricular aneurysms $(n=3)$, pulmonary arteriovenous malformations (AVMs) $(n=5)$, and proximal interruption of pulmonary artery $(n=2)$.
Here we describe imaging and various interventional methods to treat such cases.

\section{Pulmonary artery pseudoaneurysms (Rasmussen's)}

Twelve patients of pulmonary artery aneurysms were encountered, and all were treated successfully through percutaneous embolisation techniques with $100 \%$ technical and clinical success with immediate cessation of bleeding. Ten patients were embolised using a $50 \%$ mixture of $\mathrm{N}$-cyanoacrylate glue and lipiodol and two with human thrombin. Computed tomography (CT) guidance for embolisation was used in 10/12 and ultrasound (USG) in 2/12 subjects. Two representative cases are described herein.

\section{Case 1: Pulmonary artery pseudoaneurysm (Rasmussen's)}

A 21-year-old female previously treated for pulmonary tuberculosis presented to the emergency department with
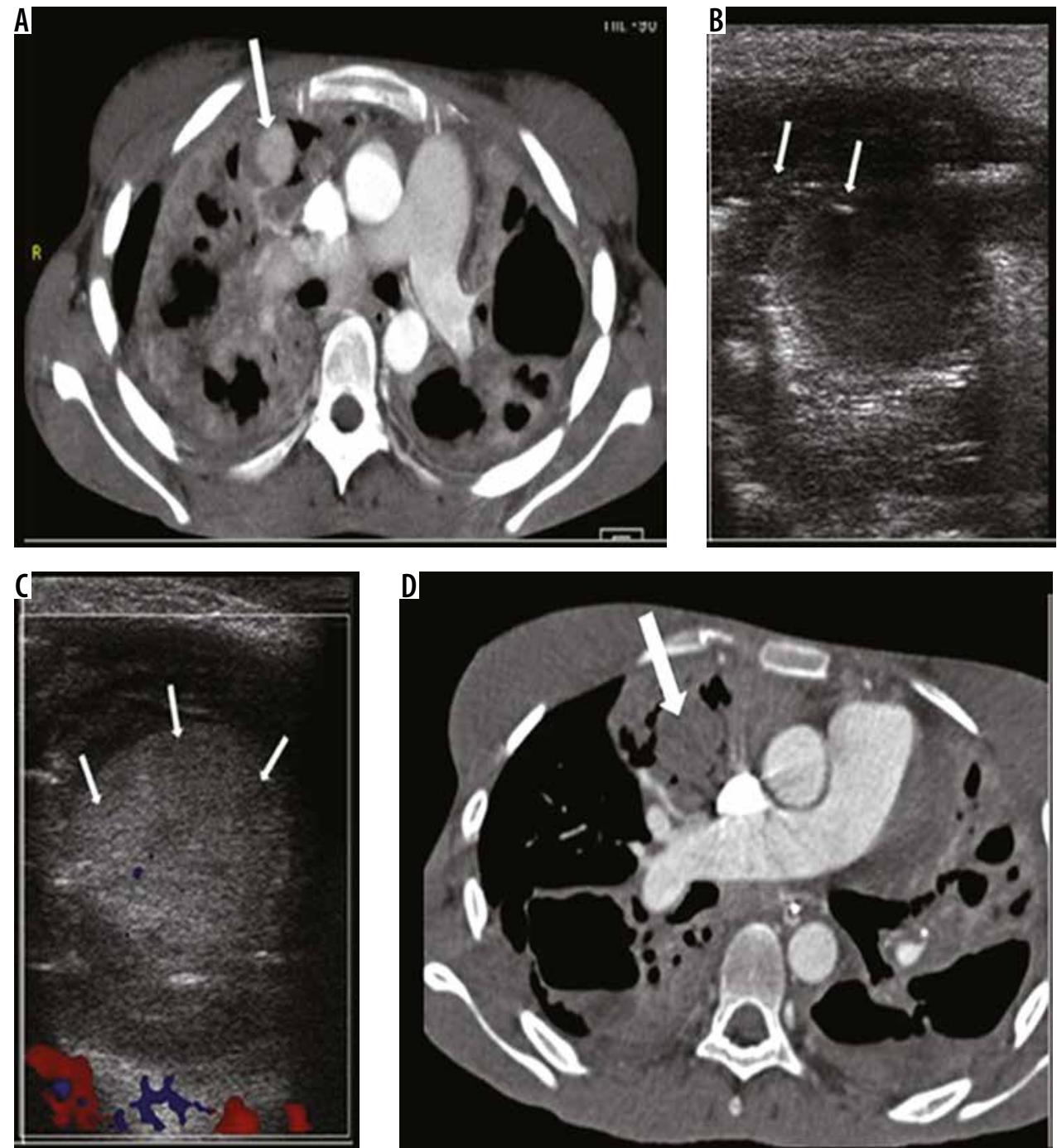

Figure 1. Axial bronchial computed tomography angiography (CTBA) image in mediastinal window reveals large areas of consolidation, with cavitations in both lungs, with a pulmonary artery pseudoaneurysm in right upper lobe (A - arrow). Ultrasound shows cystic area in right upper lobe with needle in situ during thrombin injection ( $\mathbf{B}$ - arrows), post-thrombin injection cystic pseudoaneurysm appears echogenic consistent with thrombus ( $\mathbf{C}-$ arrows), and post-thrombin injection, follow-up axial CTBA image reveals no residual opacification of the pseudoaneurysm (D - arrow) 
acute respiratory distress and massive haemoptysis. She complained of low-grade fever and an intermittent small amount of haemoptysis for the last two weeks. Bronchial CT angiography (CTBA) revealed large areas of consolidations with areas of cavitations in both lungs consistent with reactivation of tuberculosis. One cavitary area in subpleural location in the right upper lobe showed large vascular out-pouching measuring approximately $28 \times 22 \mathrm{~mm}$ in size, which arose from a small branch of pulmonary artery consistent with a Rasmussen's aneurysm (Figure 1A - thick arrow). Under ultrasound guidance a $22 \mathrm{G}$ Spinal needle (Vygon, France) was introduced into the aneurysmal sac (Figure 1B - arrows), and $500 \mathrm{IU}$ of human thrombin (Baxter, India) was injected directly into the aneurysmal sac with instant formation of thrombus (Figure 1C - arrows). Follow-up CT pulmonary angiography (CTPA) after 24 hours showed no opacification of the pseudoaneurysm (Figure 1D - thick arrow). Post procedure the patient had no episodes of haemoptysis and was discharged the next day with anti-tuberculosis treatment.

\section{Case 2: Pulmonary artery pseudoaneurysm (Rasmussen's)}

A 36-year-old male presented to the Emergency Department with an episode of massive haemoptysis (about $600 \mathrm{ml}$ ). He had been on anti-tubercular treatment for multi-resistant pulmonary tuberculosis for the past two months. On examination he was found to be pale and tachypnoeic (respiratory rate $32 /$ minute). Laboratory investigations revealed haemoglobin of $7.4 \mathrm{gm} / \mathrm{dl}$ and deranged coagulation profile (prothrombin time index of $64 \%$ ). Bronchial CT angiography demonstrated a pseudoaneurysm arising from one sub-segmental branch
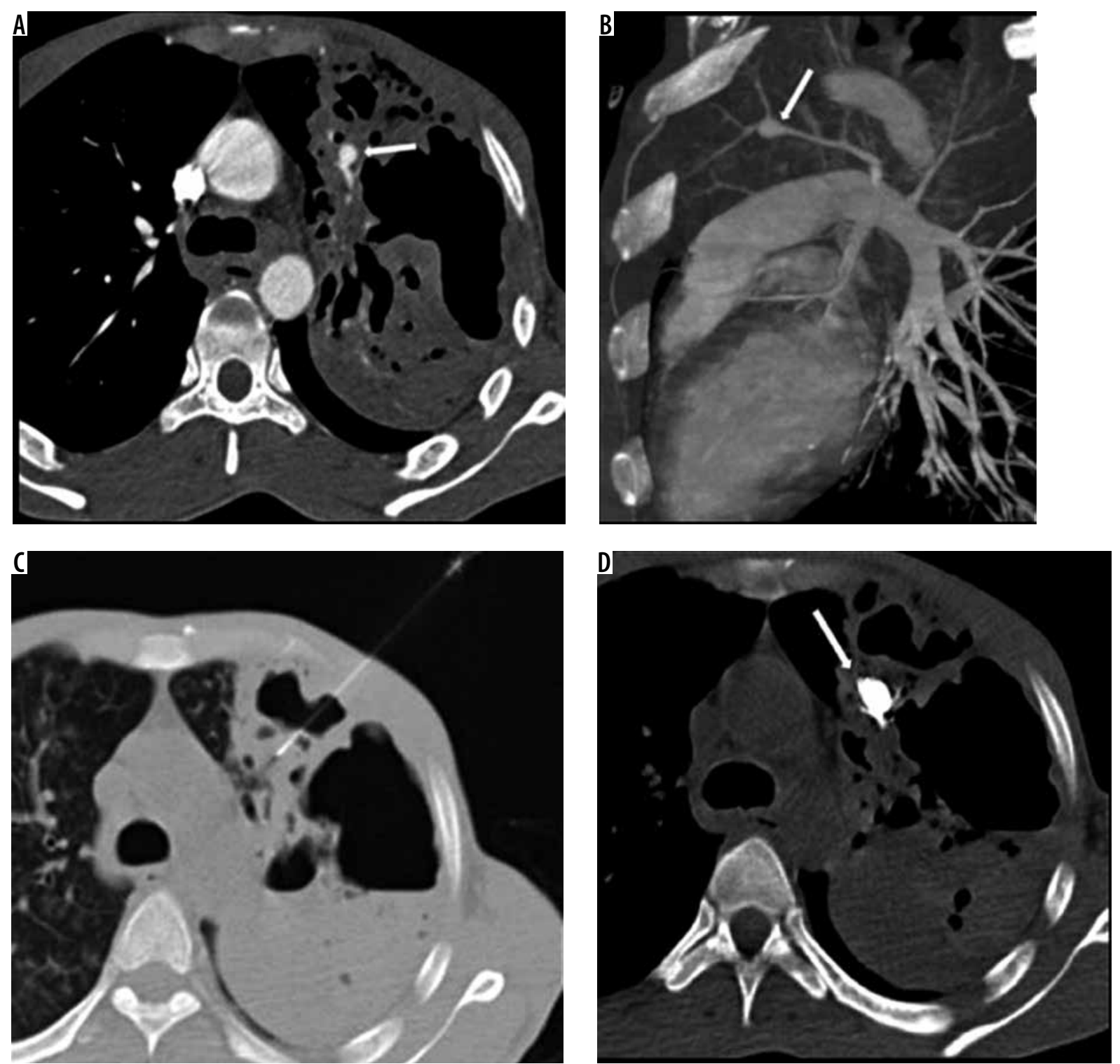

Figure 2. Axial (A) and reconstructed oblique sagittal maximum intensity projection image (B) show a pseudoaneurysm arising from a sub-segmental branch of left upper pulmonary artery in a cavitating patch of consolidation (arrow), computed tomography (CT) fluoroscopic image with needle in-situ (C), and post procedure non-contrast $\mathrm{CT}$ shows glue cast in the aneurysmal sac and offending branch of pulmonary artery (D - arrow) 
of the left upper lobe pulmonary artery (Figure $2 \mathrm{~A}$ and $\mathrm{B}$ - arrow) and patches of cavitating nodules and consolidations in both lungs. Under CT fluoroscopic guidance (Figure 2C - spinal needle in situ) $0.5 \mathrm{ml}$ of $50 \%$ mixture of $\mathrm{N}$-cyanoacrylate glue (Endocryl, Samarth Life Sciences Limited, Solan, India) and lipiodol (Lipiodol UltraFluide, Guerbet, Istanbul)was injected percutaneously into the aneurysmal sac (Figure 2D - arrow). Post procedure there were no complaints of haemoptysis, and follow-up CTPA revealed isolation of pseudoaneurysm with glue cast in-situ and patent feeding pulmonary artery (image not shown here). The patient was later discharged in a stable condition.

\section{Case 3: Pulmonary arteriovenous malformations}

A 45-year-old female presented with an episode of haemoptysis (about $100 \mathrm{ml}$ ). On evaluation with chest radiograph she was found to have mass lesion in the right mid zone with well-delineated margins and an adjacent linear radio-opacity with from hilum up to the opacity (Figure 3A). A possibility of pulmonary arteriovenous malformations (AVM) was considered that was confirmed on CTPA, which showed a partially thrombosed, well-defined vascular lesion measuring $5 \times 4.5 \mathrm{~cm}$ with a feeder from one of the dilated right upper branches of the pulmonary artery and draining into right upper pulmonary vein, consistent with pulmonary AVM (Figure 3B-D). Digital subtraction angiography (DSA) confirmed the findings of CTPA (Figure 4A, B). The AVM was embolised using coils (Nester $4 \times 14$, Cook Medical, Indiana, United States) and vascular plug (Amplatzer Vascular plug II 6-8 mm, St. Jude Medical, Minnesota United States) with obliteration of AVM (Figure 4C, D).

\section{Case 4: Internal mammary artery pseudoaneurysm}

A 15-year-old male, sputum positive on anti-tubercular treatment for the last three months, initially presented with intermittent episodes of small amounts of blood streaked sputum followed by large amounts of haemoptysis requiring admission to the Emergency Department in unstable haemodynamic condition. CTBA revealed a large pseudoaneurysm measuring $45 \times 32 \times 32 \mathrm{~mm}$ in size, arising from the left internal mammary artery (IMA) in relation to a large pocket of empyema (Figure 5A, B). Multiple other pockets of empyema and centrilobular nodules were also seen scattered in both lungs. The pseudoaneurysm was endovascularly embolised using three curled soft platinum coils $(2.0-2,3.0-3$, and
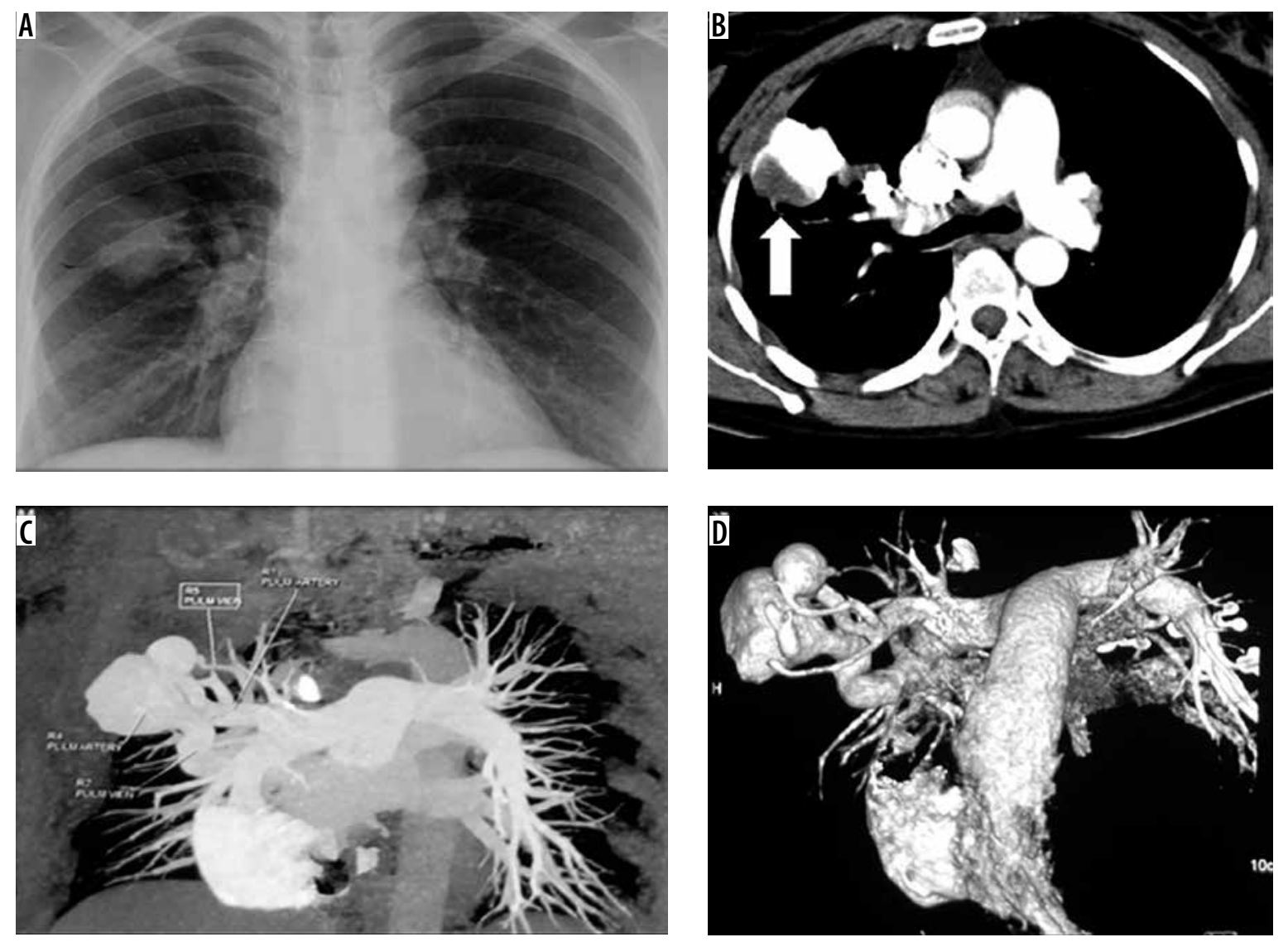

Figure 3. Frontal chest radiograph posterior-anterior view showing a well-defined radiopacity in right lung (mid zone), with dilated vessel seen up to the hilum (A). Axialbronchial computed tomography angiography image showing large vascular lesion (with partial thrombus), which is seen in communication with dilated branch of right upper pulmonary artery and right upper pulmonary vein ( $\mathbf{B}$ - thick arrow), and maximum intensity projection coronal oblique image and volume rendered images conspicuously reveals the arteriovenous malformations with feeding artery and draining veins ( $C$ and $\mathbf{D})$ 

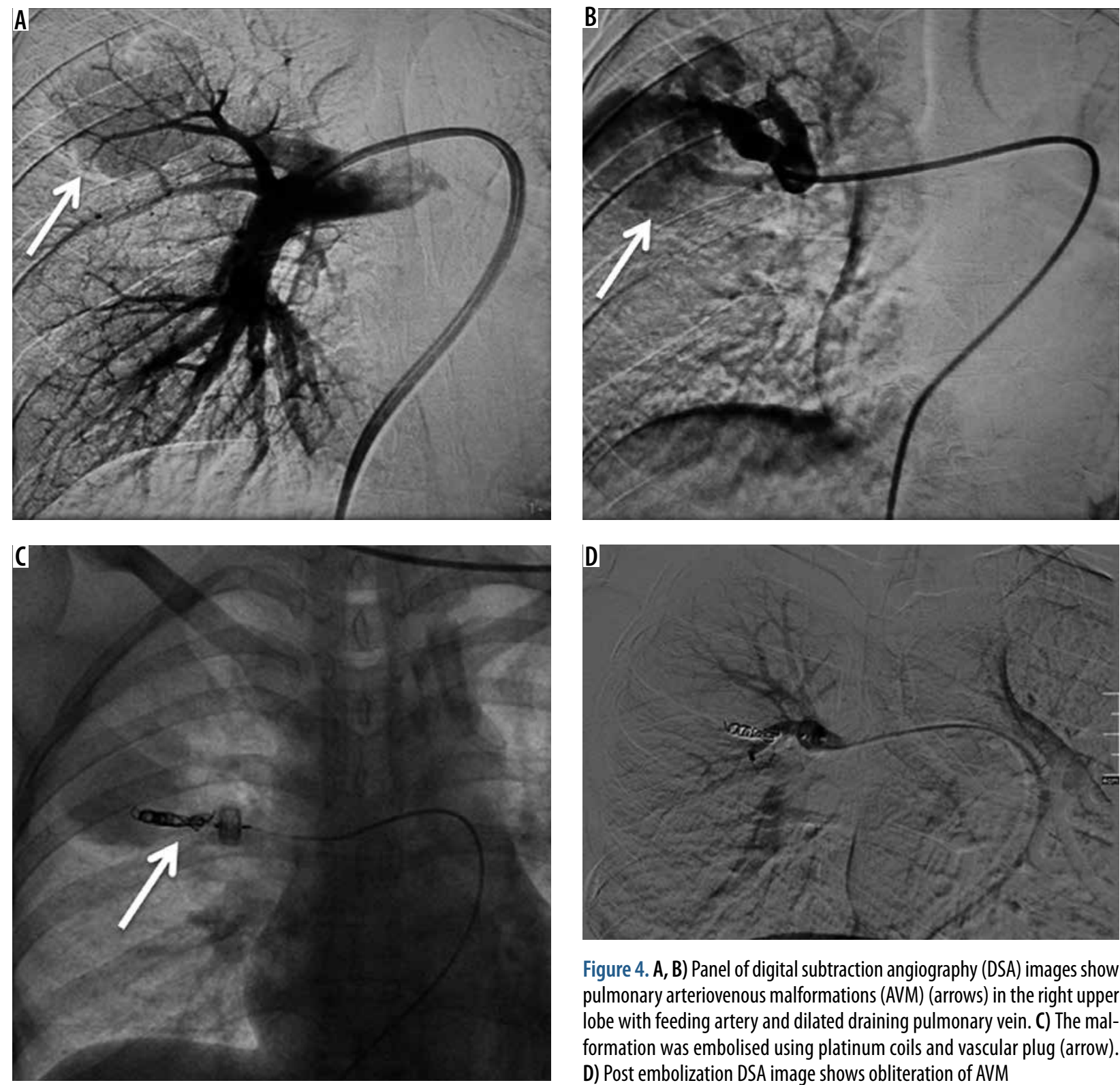

Figure 4. A, B) Panel of digital subtraction angiography (DSA) images show pulmonary arteriovenous malformations (AVM) (arrows) in the right upper lobe with feeding artery and dilated draining pulmonary vein. C) The malformation was embolised using platinum coils and vascular plug (arrow). D) Post embolization DSA image shows obliteration of AVM

3.0-3) (Cook Medical, Indiana, United States) with cessation of bleeding (Figure $5 \mathrm{C}, \mathrm{D}$ ). However, the patient's condition did not improve and he went into refractory shock to which he did not respond to treatment and expired after four hours.

\section{Case 5: Right costocervical trunk pseudoaneurysm}

A 40-year-old male treated previously for pulmonary tuberculosis four years earlier presented with recurrent haemoptysis for four days, with the total amount of approximately $1000 \mathrm{ml}$ and with a drop of haemoglobin level from $11 \mathrm{mg} / \mathrm{dl}$ to $7 \mathrm{mg} / \mathrm{dl}$. Bronchoscopy was inconclusive while chest radiography showed right upper lobe mass. CTBA showed a patch of peripheral consolidation in the right upper lobe with pleural thickening $(5 \mathrm{~mm})$ with an intensely enhancing lesion within it, arising from one of the branches of right subclavian artery, consistent with pseudoaneurysm. DSA showed a pseudoaneurysm measuring approximately $1.5 \mathrm{~cm}$ in diameter arising from a branch of the costocervical trunk (Figure 6A-C arrows). The offending artery was selectively cannulated and embolised by injecting $1 \mathrm{ml}$ of $50 \%$ mixture of $\mathrm{N}$-cyanoacrylate glue (Endocryl, Samarth Life Sciences Limited, Solan, India) and lipiodol (Lipiodol Ultra-Fluide, Guerbet, Istanbul). Post-procedure check-up angiogram revealed obliteration of pseudoaneurysm (Figure 6D). On subsequent follow-up for three months the patient had no repeat episode of haemoptysis.

\section{Left ventricular aneurysms}

Left ventricular aneurysms may rarely present with haemoptysis if they communicate with adjacent lung parenchyma. We encountered three such cases: one post-infective (pyopericardium) and two post-myocardial infarctions. All 

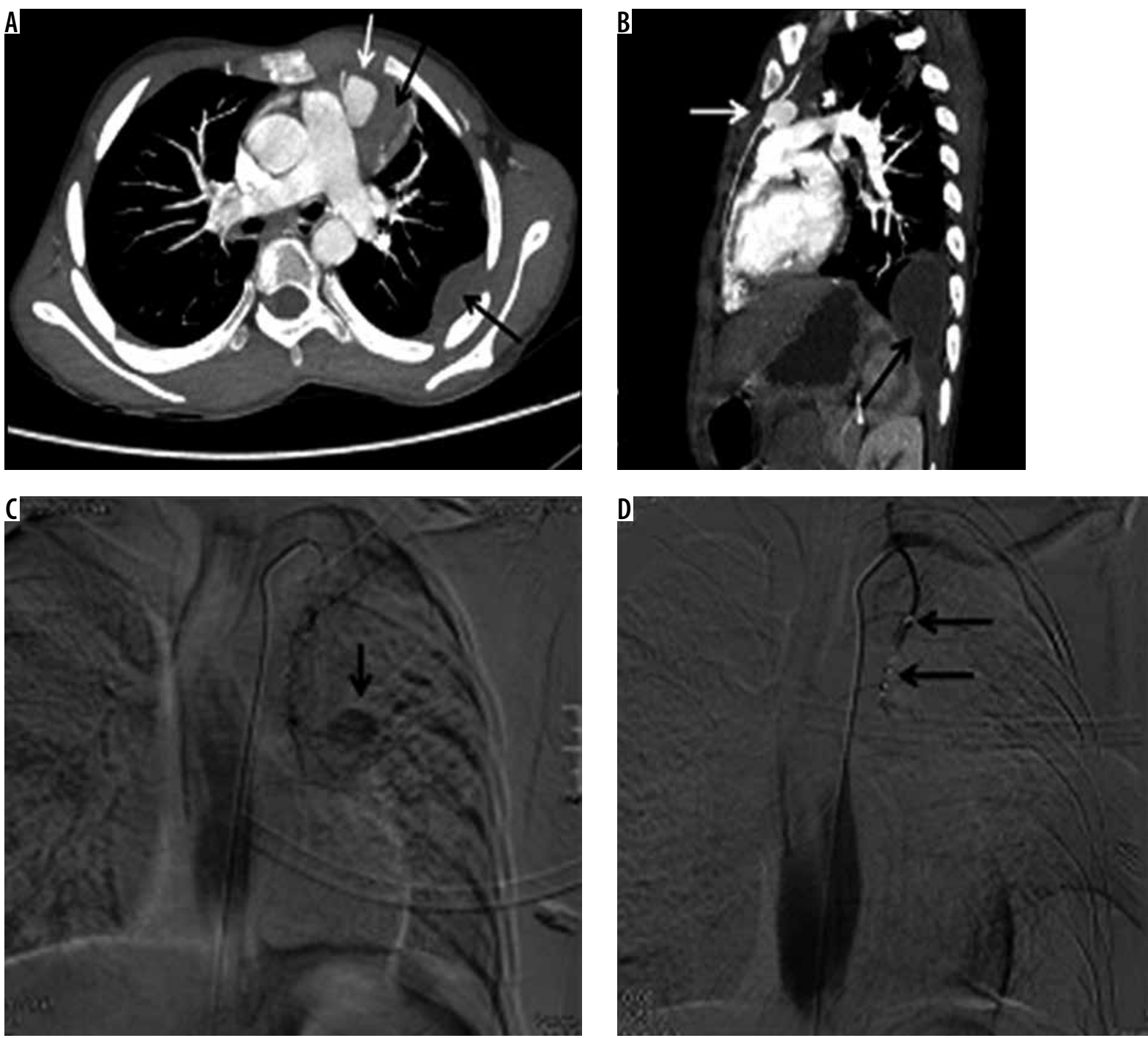

Figure 5. Bronchial computed tomography angiography axial and sagittal reformatted images showing contrast-filled outpouching (white arrows) arising from the left internal mammary artery in relation to a pocket of empyema (black arrows). A, B) Digital subtraction angiography image demonstrate left internal mammary artery showing pseudoaneurysm $(\mathbf{C}$ - arrow), and post-procedure DSA image shows coils in situ, with non-opacification of the pseudoaneurysm ( $D$ - arrows)

these cases were surgically managed. Two representative cases are presented here.

\section{Case 6: Left ventricular aneurysm}

A 60-year-old who had suffered from an inferior wall myocardial infarction 3.5 years earlier and who was managed at that time with stenting for mid-right coronary artery stenosis. For the last two years he had been having occasional streaky haemoptysis (about $10 \mathrm{ml}$ per episode). On evaluation with 2D transthoracic echocardiography, a large partially thrombosed pseudoaneurysm measuring approx. $11 \times 10 \mathrm{~cm}$ with $4.4 \mathrm{~cm}$ neck, in the submitral position, was noted. CT angiography confirmed the diagnosis (Figure 7A) and demonstrated a small communication with adjacent left lung parenchyma. Surgery showed left lateral wall of the heart adherent to the pericardium and lingular segment of the left upper lobe. Pseudoaneurysm was opened, and its connection with the left ventricle was closed using a polytetrafluoroethylene (PTFE) patch. Post-operative CT revealed normal left ventricle outline. The patient was later discharged in a stable condition.

\section{Case 7: Left ventricular aneurysm}

A 52-year-old male, a type II diabetic, was diagnosed as pyopericardium and empyema, for which he underwent pericardiectomy and drainage for infective collection with appropriate antibiotics; however, he started having recurrent haemoptysis postoperatively (250 to $750 \mathrm{ml}$ blood each in six episodes of haemoptysis). On evaluation on 2D-transthoracic echocardiography and CT angiography a small pseudoaneurysm with a $9 \mathrm{~mm}$ neck was noted arising from the anterolateral wall of the left ventricle with loculated pyopericardium and empyema (Figure 8). Emergency thoracotomy revealed haemopericardium 

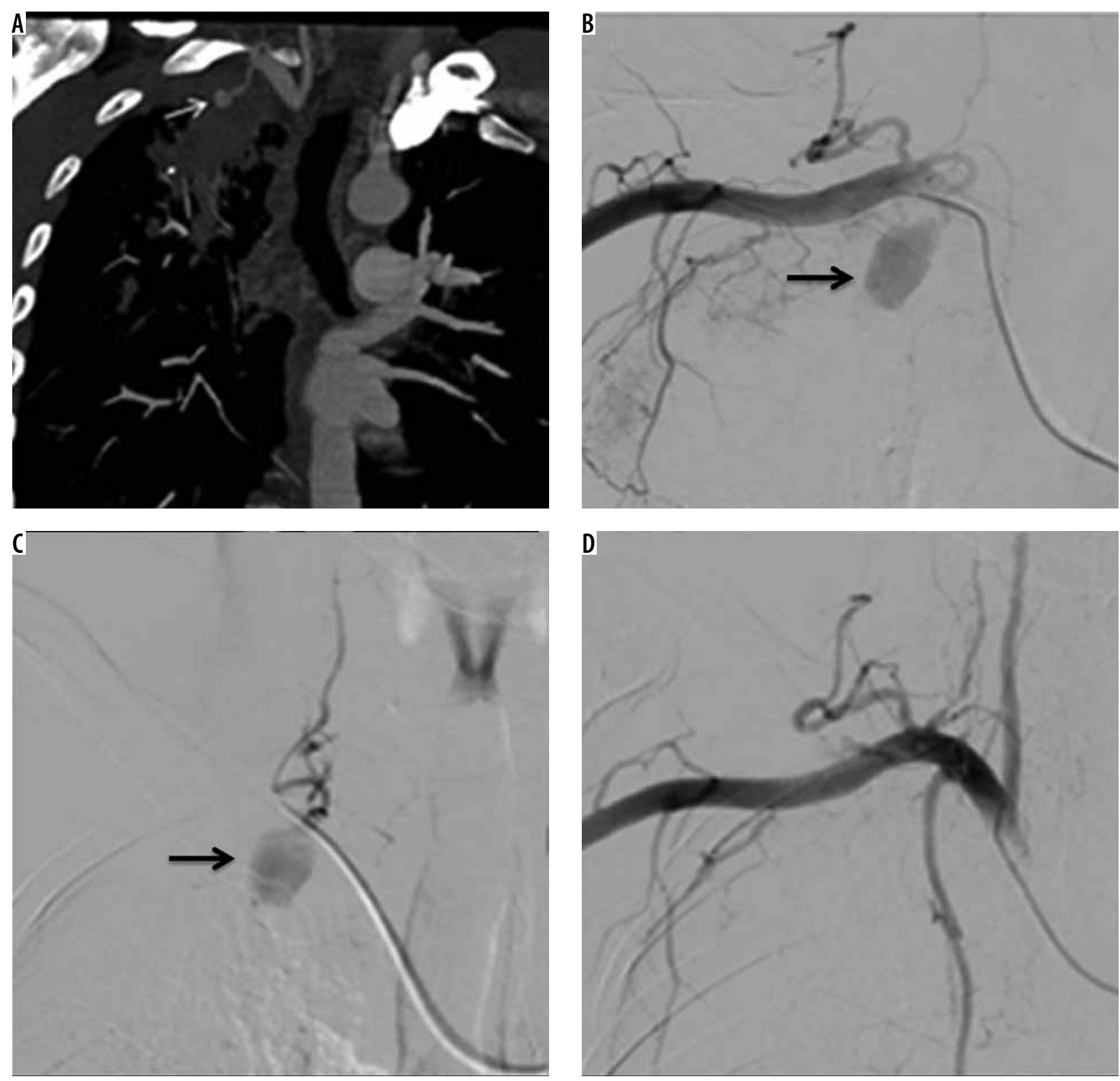

Figure 6. Bronchial computed tomography angiography maximum intensity projection image coronal plane show pseudoaneurysm arising from the intercostal branch of the right costocervical trunk ( $A$ - white arrow). Digital subtraction angiography (DSA) images show pseudoaneurysm arising from a branch of costocervical trunk (B, $C$ - arrow), and post-glue embolisation DSA image showing obliteration of pseudoaneurysm (D)

Source: Images with permission from Emergency Radiology

with a pseudoaneurysm arising from the left ventricular wall, which was seen communicating with lung parenchyma. Prolene pledged sutures were used to repair the pseudoaneurysm. However, the patient remained critical and died on the second post-operative day.

\section{Case 8: Proximal interruption of pulmonary artery}

A 32-year-old male presented with frequent episodes of streaky haemoptysis for the previous four months. CTBA showed non-visualised right pulmonary artery (Figure 9A). The main pulmonary artery and left pulmonary artery were normal in calibre and contrast opacification. Multiple collaterals were seen in mediastinum and bilateral pleura. They were arising from the internal mammary artery, intercostal arteries, and bronchial arteries. In addition, the right lung was small in size. The left lung showed compensatory hypertrophy with herniation to the contralateral side (Figure 9 B). Based on these findings, diagnosis of proximal interruption of the right pulmonary artery was made. Embolisation of collaterals to treat haemoptysis was planned; however, the patient refused treatment.

\section{Discussion}

Haemoptysis is a serious and life-threatening condition that warrants urgent investigation and treatment. For prognostication not only the volume of the blood 

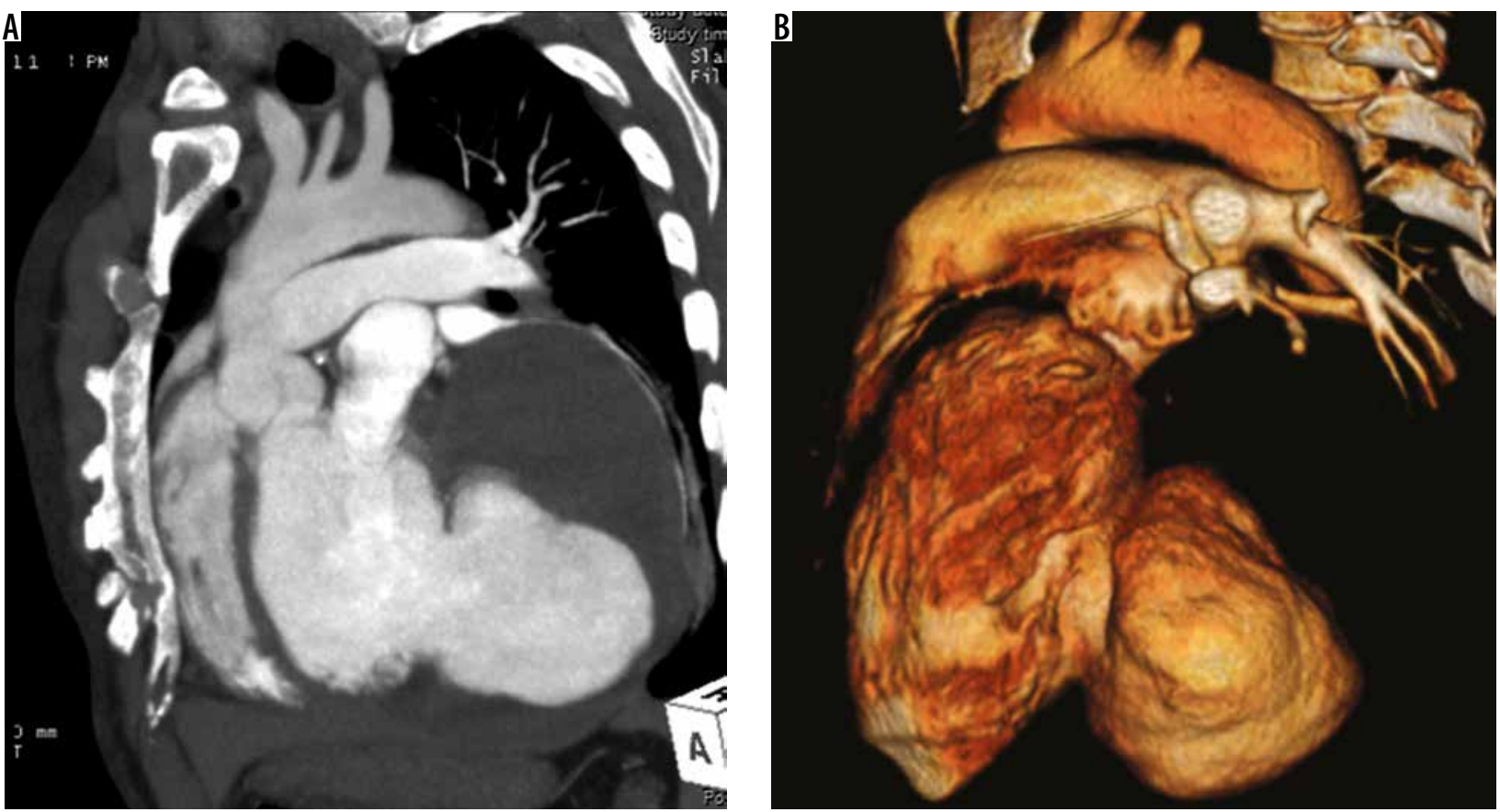

Figure 7. Oblique coronal maximum intensity projection (A) and volume-rendered (B) computed tomography angiography images show a large pseudoaneurysm arising from posterolateral wall of the left ventricle

expectorated is important but also the patient's cardiovascular and respiratory reserve. Haponik et al. in a survey noted that $28 \%$ of chest physicians had encountered a death from massive haemoptysis in the previous one year [8]. An appropriate diagnostic modality to evaluate the source of haemoptysis is of paramount importance. Conventional radiography, bronchoscopy, chest CT, and thoracic angiography are various options available and are used depending upon the expertise, availability, and underlying disease. Chest radiograph is a basic and readily available diagnostic tool; however, it is diagnostic in only $50 \%$ of cases [4]. Fibreoptic bronchoscopy (FOB) shows 10-43\% overall diagnostic accuracy [4,9-11]. Bronchial CT angiography (CTBA) is a more useful and robust non-invasive investigation for evaluating the thoracic and upper abdominal vasculature including lung and mediastinum to identify the source of haemorrhage. CT scan leads to specific diagnosis in $50 \%$ of cases in which FOB findings are non-diagnostic, and 39-88\% of cases in which chest radiographs are not diagnostic $[4,9,10,12]$.

The lungs get $99 \%$ of their blood supply from the pulmonary arteries and 1\% from the bronchial arteries [13]. There is anastomosis between them at the level of the vasa vasorum leading to right to left shunt, which amounts to approximately $5 \%$ of cardiac output $[14,15]$. These anastomotic vessels are prone to rupture. When pulmonary blood supply is reduced (e.g. in thrombo-embolism, vasculitis, and inflammatory conditions) there is a corresponding increase in bronchial artery supply [16-21]. Vascular endothelial growth factor (VEGF) and angiopoietin levels increase in inflammatory conditions and neoplastic dis-

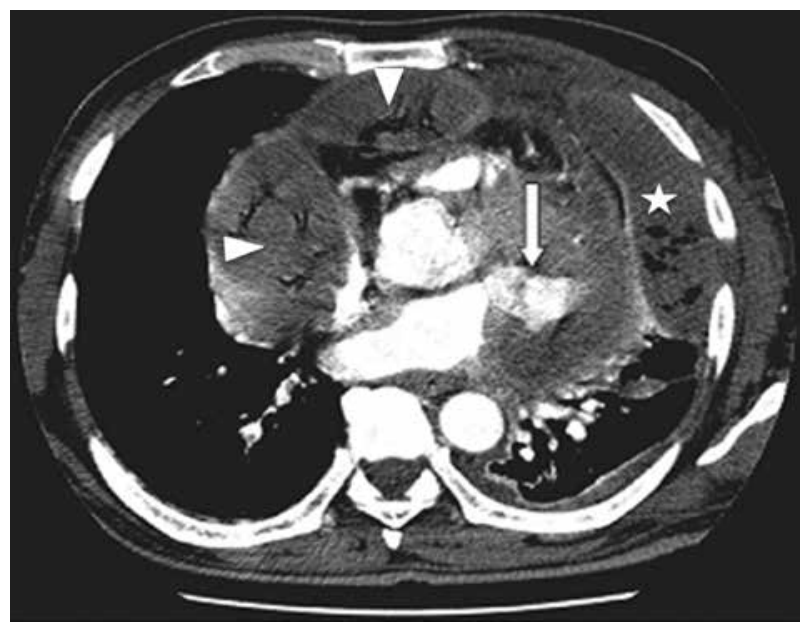

Figure 8. Axial computed tomography angiography study shows pseudoaneurysm arising from left ventricle (arrow). In addition, left empyema (asterisk) is seen with pericardial effusion (arrow heads)

eases of the lung leading to neovascularisation, vascular remodelling, and increased collateral supply from nearby systemic vessels $[22,23]$. These vessels are fragile and prone to rupture. On angiography, they appear as dilated tortuous vessels and as systemic to pulmonary arterial shunts, often with contrast material extravasation at the site of bleeding. Most common aetiologies are bronchiectasis, chronic bronchitis, tuberculosis, and malignancy.

Vascular sources of haemoptysis can be divided into bronchial (90\%) and non-bronchial (10\%) [5]. In the series herein we have elaborated imaging and interventional management in non-bronchial vascular causes of haemoptysis in our institution from 2008 to 2013. 

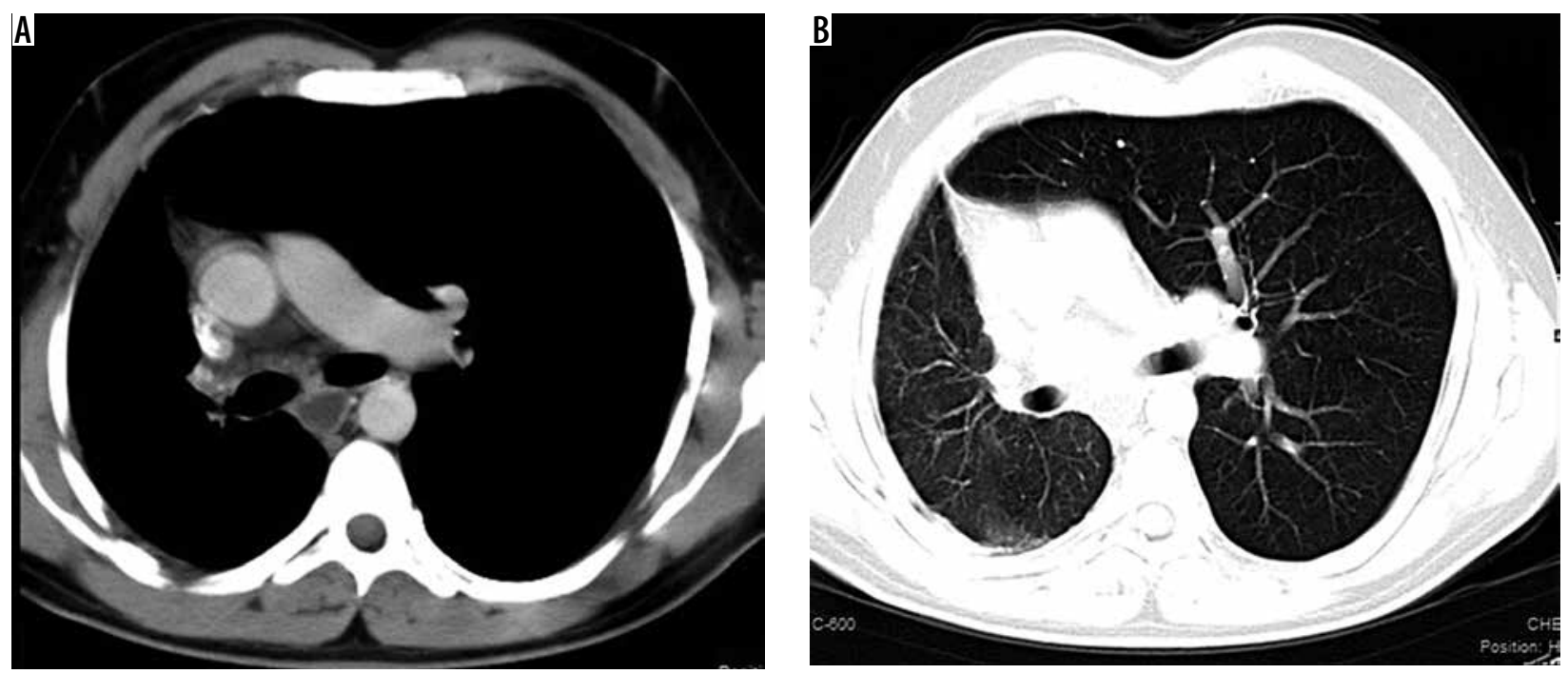

Figure 9. Axial bronchial computed tomography angiography images in mediastinal (A) and lung (B) window settings show absent right pulmonary artery but normal calibre main pulmonary artery and left pulmonary arteries, and small right lung with compensatory hypertrophy of left lung with herniation to the contralateral side, respectively

Pulmonary artery accounts for approximately $5-10 \%$ of the non-bronchial causes of haemoptysis. Various pulmonary pathologies leading to haemoptysis are pulmonary emboli, Rasmussen's aneurysm, Dieulafoy's disease, and pulmonary AVMs [24].

Pulmonary artery pseudoaneurysms occurring in cases of fibro-cavitary tuberculosis are termed Rasmussen's aneurysms [25]. In an autopsy series done in patients with chronic pulmonary tuberculosis with cavitations, 45 out of 1114 had pulmonary pseudoaneurysm [26]. In another series, six out of 72 patients who had under gone transcatheter technique for haemoptysis were found to have pulmonary artery pseudoaneurysms [27]. Souders and Smith [28] concluded that in acute tuberculosis, bleeding occurs because of necrosis of a small pulmonary artery or vein and is of small volume, whereas in chronic fibro-ulcerative tuberculosis, haemorrhage occurs due to rupture of an aneurysm through the wall of the chronic cavity. Endovascular occlusion with coils of the pulmonary artery branch supplying the aneurysmal sac as well as filling of the sac itself with coils have been described as treatment modalities [27,29-31]. Occlusion of the pseudoaneurysm or the parent vessel can be done through transcatheter embolisation or with percutaneous injection of thrombin or N-butyl cyanoacrylate glue [32]. In our series we had embolised all $(n=12)$ the pulmonary artery aneurysms of tubercular aetiology (Rasmussen's) through guided (ultrasound or CT) percutaneous injection of liquid embolisation agents (human thrombin or $\mathrm{N}$-butyl cyanoacrylate glue-lipiodol mixture). Endovascular embolisation of the offending pulmonary artery branch is well described in literature; however, this technique may be difficult because these patients have poor respiratory lung reserves and the aneurysm, if peri- pheral and small in size, may be missed on angiography due to respiratory motion artefacts. Percutaneous, on other hand, is very effective, with $100 \%$ technical and clinical success. Other advantages of percutaneous therapy are its good cost effectiveness, permanent embolisation - especially with $N$-butyl cyanoacrylate glue, and the fact that it can be performed in patients with deranged coagulation profiles and poor cardio-vascular-respiratory reserves.

Pulmonary AVMs are a relatively uncommon cause of haemoptysis. After the first description of pulmonary AVM by Churton in 1897 [33], more than 500 have been described. AVMs are direct arterial-to-venous connections without any intervening capillary bed. They are classified as either simple or complex. Simple are ones with single feeding artery and single draining vein, and complex are ones with two or more of each [34]. Thirty-five per cent of patients of Rendu-Osler-Weber syndrome are associated with multiple AVMs [35]. The most common symptom of pulmonary AVM is dyspnoea followed by haemoptysis. Haemoptysis may be fatal due to rupture of the thin wall of the aneurysmal centre of the AVM. All symptomatic AVMs or pulmonary AVMs larger than $2 \mathrm{~cm}$ should be treated [36,37]. Transcatheter embolisation with coils, vascular plugs, and detachable balloons is the treatment of choice $[38,39]$. Non-bronchial systemic arteries that can cause haemoptysis are the brachiocephalic artery, subclavian artery, thyrocervical trunk, costocervical artery, axillary artery, intercostal arteries, IMA, inferior phrenic artery, gastric artery, and branches of celiac axis [40]. They do not course parallel to bronchi and enter lung parenchyma through the adherent pleura or through inferior pulmonary ligament. Their presence should be suspected when pleural thickening is more than $3 \mathrm{~mm}$ with the presence of enhancing arteries within the extrapleural fat. They are 
usually seen in patients with chronic pulmonary inflammatory disease, especially those that have associated pleural involvement [41]. These arteries will lead to recurrent haemoptysis following bronchial artery embolisation, if not recognised. CT angiographic evaluation for haemoptysis, if possible, is thus advised before angiography and bronchial artery embolisation and should always include upper abdomen and supra-aortic great vessels, to allow the search for vessels that may be amenable to embolotherapy $[40,41]$. On catheter angiography, these vessels may be unusually prominent, tortuous, or may show abnormal contrast blush. Pseudoaneurysms of these vessels are very rare. We encountered a case of IMA pseudoaneurysm and costocervical pseudoaneurysm, as described earlier.

Internal mammary artery pseudoaneurysm as a cause of haemoptysis is rare. It occurs if there is communication of the pseudoaneurysm with a bronchus. The causes of IMA pseudoaneurysm that have been described include sternotomy, insertion of central venous catheter, trauma, pacemaker leads, and percutaneous biopsy [42]. IMA pseudoaneurysms caused by chest wall infections (e.g. Staphylococcus, Tuberculosis, Actinomycosis, or fungal) are rarer [43]. Only a few cases have been reported previously [42-47]. Endovascular embolisation is an effective and safe alternative to surgical treatment [47].

To our knowledge, only two cases of costocervical pseudoaneurysm have been described before, one following internal jugular vein (IJV) cannulation and one following bullectomy with pleural abrasions for spontaneous pneumothorax [48,49]. The costocervical artery is a branch of the subclavian artery. It has two parts: cervical and costal. The costal part of the costocervical arteries is involved in pathology affecting the pleural space. Endovascular embolisation is the treatment of choice [50], and we had also embolised our case with endovascular injection of N-butyl cyanoacrylate glue-lipiodol mixture. The previous two reported cases were also treated by endovascular embolisation techniques.

Left ventricular aneurysm is one of the rare causes of haemoptysis, with only a few reports in literature. Left ventricular aneurysm occurs due to rupture of the left ventricular wall, with adherence to pericardium and fibrous tissue. The various aetiologies are myocardial infarction, cardiac surgery, trauma, infection, surgery, and ablation [51,52-59]. Infectious causes leading to ventricular pseudoaneurysm are abscess, pericarditis, and infective endocarditis, with the most common aetiological organism being Staphylococcus aureus [55]. Haemoptysis is a very rare presentation, occurring due to ventriculopulmonary communication [56]. It has poor prognosis if not diagnosed on time. CT scan exactly delineates the extent of pseudoaneurysm and involvement of cardiac and noncardiac structures. Surgery is the treatment of choice.

Proximal interruption of the pulmonary artery is an uncommon developmental anomaly of the sixth bran- chial arch and is described as the absence or termination of the pulmonary artery within $1 \mathrm{~cm}$ of its origin $[60,61]$. Absence of the pulmonary artery leads to perfusion of the lung through bronchial arteries and the branches of the intercostal, internal mammary, subclavian, and innominate arteries. Hypervascularity and hypertrophy of these arteries lead to vascular ectasia in the bronchial submucosa, and rupture of ecstatic vascular channels leads to haemoptysis. Interruption of right pulmonary artery is more common than that of the left side, which when present is usually associated with right aortic arch, septal defects, patent ductus arteriosus, and tetralogy of Fallot [62]. The diagnosis of proximal interruption of the pulmonary artery is usually straightforward on chest CT scans, which show interrupted/absent pulmonary artery with ipsilateral volume loss of the lung. Enlarged intercostal and transpleural arteries are seen as fine linear opacities and serrated thickening of the pleura representing anastomosis of peripheral branches of the pulmonary artery with transpleural collateral vessels. Definitive treatment for this entity is either pneumonectomy with ligation of collaterals or reanastomosis of the peripheral pulmonary artery with the main pulmonary artery [62]. Transcatheter embolisation of aorto-pulmonary collaterals is a viable option for treatment of haemoptysis in some cases.

\section{Conclusions}

Haemoptysis most commonly arises from bronchial arterial sources; however, at times it may have a non-bronchial source of bleeding, which might persist if standard bronchial artery embolisation is done without considering other non-bronchial causes. Henceforth all efforts should be made to identify all possible causes of haemoptysis, and bronchial CT angiography (CTBA) if feasible must always be considered before bronchial artery embolisation. CTBA precisely identifies source of haemorrhage and vascular anatomy, which helps interventional radiologists in preprocedural planning. Percutaneous embolisation techniques especially for pulmonary artery pseudoaneurysms (Rasmussen's) is rewarding, with 100\% technical and clinical success and scores over angiographic embolisation because these patients have poor respiratory reserve and breath hold. Pulmonary AVMs should be embolised using coils or vascular plugs, and other systemic arteries with either coils or N-butyl cyanoacrylate glue-lipiodol mixture as per pathology and expertise.

\section{Conflict of interest}

The authors report no conflict of interest. 


\section{References}

1. Fraser RS, Pare P, Pare PD. Hemoptysis. In: Diseases of the chest. Fraser RS, Pare P, Pare PD (eds.). Saunders, Philadelphia 1988; 394-399.

2. Marshall TJ, Jackson JE. Vascular intervention in the thorax: bronchial artery embolization for hemoptysis. Eur Radiol 1997; 7: 12211227.

3. Jean-Baptiste E. Clinical assessment and management of massive hemoptysis. Crit Care Med 2000; 28: 1642-1647.

4. Hirshberg B, Biran I, Glazer M, Kramer MR. Hemoptysis: etiology, evaluation, and outcome in a tertiary referral hospital. Chest 1997; 112: 440-444.

5. Remy-Jardin M, Bouaziz N, Dumont P, et al. Bronchial and non-bronchial systemic arteries at multi- detector row CT angiography: comparison with conventional angiography. Radiology 2004; 233: 741-749.

6. Keller FS, Rosch J, Loflin TG, et al. Nonbronchial systemic collateral arteries: significance in percutaneous embolotherapy for hemoptysis. Radiology 1987; 164: 687-692.

7. Khalil A, Fartoukh M, Tassart M, et al. Role of MDCT in identification of the bleeding site and the vessels causing hemoptysis. AJR Am J Roentgenol 2007; 188: W117-W125

8. Haponik EF, Fein A, Chin R. Managing life-threatening hemoptysis: has anything really changed? Chest 2000; 118: 1431-1435.

9. Naidich DP, Funt S, Ettenger NA, Arranda C. Hemoptysis: CT-bronchoscopic correlations in 58 cases. Radiology 1990; 177: 357-362.

10. McGuinness G, Beacher JR, Harkin TJ, et al. Hemoptysis: prospective high-resolution CT/bronchoscopic correlation. Chest 1994; 105 1155-1162.

11. Tak S, Ahluwalia G, Sharma SK, Mukhopadhya S, Pande JN. Haemoptysis in patients with a normal chest radiograph: bronchoscopy-CT correlation. Australas Radiol 1999; 43: 451-455.

12. Abal AT, Nair PC, Cherian J. Haemoptysis: aetiology, evaluation, and outcome - a prospective study in a third-world country. Respir Med 2001; 95: 548-552.

13. Millar AB, Boothroyd AE, Edwards D, et al. The role of computed tomography (CT) in the investigation of unexplained hemoptysis. Respir Med 1992; 86: 39-44.

14. Deffebach M, Butler J. The bronchial circulation and lung edema. In: Heart-lung interactions in health and disease. Scharf S, Cassidy S (eds.). Dekker, New York 1989; 131-151.

15. Pump KK. The bronchial arteries and their anastomoses in the human lung. Dis Chest 1963; 43: 245-255.

16. Deffebach ME, Charan NB, Lakshminarayan S, Butler J. The bronchial circulation: small, but a vital attribute of the lung. Am Rev Respir Dis 1987; 135: 463-481.

17. Kauczor HU, Schwickert HC, Mayer E, et al. Spiral CT of bronchial arteries in chronic thromboembolism. J Comput Assist Tomogr 1994; 18: 855-861.

18. Yoon W, Kim YH, Kim JK, et al. Bronchovascular adjustments after pulmonary embolism. J Appl Physiol 1980; 49: 476-481.

19. Lacombe P, Qanadli SD, Jondeau G, et al. Treatment of hemoptysis in Behcet syndrome with pulmonary and bronchial embolization. J Vasc Interv Radiol 1997; 8: 1043-1047.
20. Matsunaga N, Hayashi K, Sakamoto I, et al. Coronary-to-pulmonary artery shunts via the bronchial artery: analysis of cine angiographic studies. Radiology 1993; 186: 877-882.

21. Nakabayashi K, Kurata N, Nangi N, et al. Pulmonary artery involvement as first manifestation in three cases of Takayasu arteritis. Int J Cardiol 1996; 54: S177-S183.

22. McDonald DM. Angiogenesis and remodeling of airway vasculature in chronic inflammation. Am J Respir Crit Care Med 2001; 164: S39-S45.

23. Jeffery PK. Remodeling in asthma and chronic obstructive lung disease. Am J Respir Crit Care Med 2001; 164: S28-S38.

24. Remy-Jardin M, Bouaziz N, Dumont P, et al. Bronchial and non-bronchial systemic arteries at multi-detector row CT angiography: comparison with conventional angiography. Radiology 2004; 233: 741-749.

25. Rasmussen V. On hemoptysis: especially when fatal, in its anatomical and clinical aspects. Edinburgh Med J 1868; 14: 385.

26. Auerbach O. Pathology and pathogenesis of pulmonary artery aneurysm intuberculous cavity. Am Rev Tuberc 1939; 39: 99-115.

27. Remy J, Lemaitre L, Lafitte JJ, et al. Massive hemoptysis of pulmonary arterial origin: diagnosis and treatment. AJR 1984; 143: 963-969.

28. Souders CR, Smith AT. The clinical significance of hemoptysis. N EngI J Med 1952; 20: 790-793.

29. Remy J, Smith M, Lemaitre L, et al. Treatment of massive hemoptysis by occlusion of a Rasmussen aneurysm. AJR Am J Roentgenol 1980; 135: 605-606.

30. Santelli ED, Katz DS, Goldschmidt AM, Thomas HA. Embolization of multiple Rasmussen aneurysms as a treatment of hemoptysis. Radiology 1994; 193: 396-398.

31. Davidoff $A B$, Udoff EJ, Schonfeld SA. Intraaneurysmal embolization of a pulmonary artery aneurysm for control of hemoptysis. AJR Am J Roentgenol 1984; 142: 1019-1020.

32. Lee K, Shin T, Choi J, Kim Y. Percutaneous injection therapy for a peripheral pulmonary artery pseudoaneurysms after failed transcatheter coil embolization. Cardiovasc Intervent Radiol 2008; 31: 1038-1041.

33. Churton T. Multiple aneurysms of pulmonary artery. BMJ 1897; 1: 1223.

34. Goodenberger DM. Pulmonary arteriovenous malformation. In: Fishmans pulmonary diseases and disorders. $4^{\text {th }}$ ed. Fishman AP (ed.). McGraw Hill, China 2008; 1467-1483.

35. Donnelly LF. Chest. In: Diagnostic imaging pediatrics. Donnelly LF (ed.). Amirsys, Salt Lake City 2005; 118-120.

36. Gossage JR, Kanj G. Pulmonary arteriovenous malformations: a state of the art review. Am J Respir Crit Care Med 1998; 158: 643-661.

37. Ference BA, Shannon TM, White RI, et al. Life threatening pulmonary hemorrhage with pulmonary arteriovenous malformations and hereditary hemorrhagic telangiectasia. Chest 1994; 106: 13871390.

38. White RI Jr, Lynch-Nyhan A, Terry P, et al. Pulmonary arteriovenous malformations: techniques and long-term outcome of embolotherapy. Radiology 1988; 169: 663-669. 
39. Lee DW, White RI Jr, Egglin TK, et al. Embolotheraphy of large pulmonary arteriovenous malformations: long-term results. Ann Thorac Surg 1997; 64: 930-940.

40. Bruzzi JF, Remy-Jardin M, Delhaye D, et al. Multi-detector row CT of hemoptysis. Radiographics 2006; 26: 3-22.

41. Yıldız AE, Arıyürek OM, Akpınar E, et al. Multidetector CT of bronchial and non-bronchial systemic arteries. Diagn Interv Radiol 2011; 17: 10-17.

42. Nasir A, Viola N, Livesey SA. Iatrogenic pseudoaneurysms of internal mammary artery: case report and literature review. J Card Surg 2009; 24: 355-356.

43. Yadav MK, Bhatia A, Kumar S, Khandelwal N. Internal mammary artery pseudoaneurysm: A fatal complication of tubercular empyema. Lung India 2013; 30: 341-343.

44. Deshmukh H, Prasad SR, Patankar T, Zankar M. Internal mammary artery pseudoaneurysms complicating chest wall infection in children: diagnosis and endovascular therapy. Clin Imaging 2001; 25: 396-399.

45. Sanchez FW, Freeland PN, Bailey GT, Vujic I. Embolotherapy of a mycotic pseudoaneurysm of the internal mammary artery in chronic granulomatous disease. Cardiovasc Intervent Radiol 1985; 8: 43-45.

46. Wani NA, Rawa IA, Pala NA, Kosar T. Pseudoaneurysm of internal mammary artery caused by pulmonary actinomycosis. Br J Radiol 2010; 83: e235-e238.

47. Whigham CJ Jr, Fisher RG, Goodman CJ, et al. Traumatic injury of the internal mammary artery: Embolization versus surgical and non-operative management. Emerg Radiol 2002; 9: 201-207.

48. Lang EV, Picus D. Delayed rupture of a pseudoaneurysm of the costocervical trunk: treatment with therapeutic embolization. Radiology 1991; 78: 352

49. Yu D, Sun XW, Chen C, et al. Endovascular coil embolization of a costocervical trunk pseudoaneurysm after bullectomy with pleural abrasion. Vasc Endovascular Surg 2014; 48: 74-76.

50. Singhal M, Girgani D, Lal A, et al. An unusual cause of hemoptysis: costocervical trunk pseudoaneurysm. Emerg Radiol 2011; 18: 53-55.

51. Vijayvergiya R, Chongtham DS, Thingnam SK, et al. Left ventricular pseudoaneurysm with infective pericarditis: a rare cause of intractable hemoptysis. Angiology 2008; 59: 507-509.
52. Davidson KH, Parisi AF, Harrington JJ, et al. Pseudoaneurysm of the left ventricle: an unusual echocardiographic presentation. Review of the literature. Ann Intern Med 1977; 86: 430-433.

53. Kovac JD, Spyt TJ, Firmin RK, et al. Chronic haemoptysis as delayed complication of ventricular aneurysmectomy. Int J Cardiol 1999; 69: 299-303.

54. Alizade E, Guler A, Acar G, et al. Multimodality cardiac imaging of a giant left ventricular pseudoaneurysm. Eur J Echocardiogr 2011; 12: 550 .

55. Arifi AA, Koehler A, Hwong TM, et al. Staphylococcus aureuspancarditis complicated by a left ventricular pseudoaneurysm. Asian Cardiovasc Thorac Ann 2004; 12: 86-88.

56. Vijayvergiya R, Pattam J, Rana SS, et al. Giant left ventricular pseudoaneurysm presenting with hemoptysis. World J Cardiol 2012; 4: 218-220.

57. Kansiz E, Hatemi AC, Tongut A, et al. Surgical treatment of a giant postero-inferior left ventricular pseudoaneurysm causing severe mitral insufficiency and congestive heart failure. Ann Thorac Cardiovasc Surg 2012; 18: 151-155.

58. Fox SA, Templeton C, Hancock-Friesen C, Chen R. Commotio cordis and ventricular pseudoaneurysm. Can J Cardiol 2009; 25: 237-238.

59. Lee YH, Hou CJ, Hung CL, Tsai CH. Silent and huge left ventricular pseudoaneurysm with left atrial compression: dedicated spatial resolution and geometry by 3-dimensional echocardiography. J Am Soc Echocardiogr 2007; 20: 772.e5-772.e9

60. Kieffer SA, Amplatz K, Anderson RC, Lillehei CW. Proximal interruption of a pulmonary artery. Am J Roentgenol Radium Ther Nucl Med 1965; 95: 592-597.

61. Sherrick DW, Kincaid OW, Dushane JW. Agenesis of a main branch of the pulmonary artery. Am J Roentgenol Radium Ther Nucl Med 1962; 87: 917-928.

62. Rene M, Sans J, Dominguez J, et al. Unilateral pulmonary artery agenesis presenting with hemoptysis: treatment by embolization of systemic collaterals. Cardiovasc Intervent Radiol 1995; 18: 251-254. 